\title{
Bridge to durable left ventricular assist device for refractory cardiogenic shock
}

\author{
Daisuke Yoshioka, MD, ${ }^{\mathrm{a}}$ Hiroo Takayama, MD, ${ }^{\mathrm{a}}$ Arthur R. Garan, MD, ${ }^{\mathrm{b}}$ Veli K. Topkara, MD, ${ }^{\mathrm{b}}$ \\ Jiho Han, BS, ${ }^{\mathrm{a}}$ Boyganzi Li, PhD, ${ }^{\mathrm{a}}$ Paul Kurlansky, MD, ${ }^{\mathrm{a}}$ Melana Yuzefpolskaya, MD, ${ }^{\mathrm{b}}$ \\ Paolo C. Colombo, MD, ${ }^{b}$ Yoshifumi Naka, MD, ${ }^{a}$ and Koji Takeda, MD $^{\mathrm{a}}$
}

\begin{abstract}
Objective: The role of short-term mechanical circulatory support has increased in patients with refractory cardiogenic shock. However, limited data exist on the outcomes of a bridge to a durable left ventricular assist device strategy using shortterm mechanical circulatory support.

Methods: We retrospectively reviewed 382 patients who underwent continuousflow left ventricular assist device insertion between 2004 and 2014. Of these, 45 $(12 \%)$ were bridged with short-term mechanical circulatory support devices for refractory cardiogenic shock. We analyzed early and midterm outcomes in this bridged cohort. Multivariate Cox proportional hazards modeling was performed to evaluate the predictor of overall death in the entire cohort.
\end{abstract}

Results: The mean age of the bridged cohort was $53 \pm 10$ years, and $87 \%$ were male. The types of initial support included percutaneous devices in 24 patients $(53 \%)$ and external continuous-flow ventricular assist device in 21 patients $(47 \%)$. The median duration of short-term mechanical circulatory support was 14.0 (interquartile range, 7.5-29.5) days. The short-term mechanical circulatory support significantly improved end-organ function and hemodynamics. After conversion to durable left ventricular assist device insertion, in-hospital mortality was $18 \%$. The incidence of right ventricular assist device use was high at $27 \%$. The overall survival was $70 \%$ and $62 \%$ at 1 and 2 years, respectively. Cox multivariate hazard analysis in the entire cohort demonstrated that the use of a postoperative right ventricular assist device was a significant predictor of overall death (hazard ratio, $4.04 ; P<.001 ; 95 \%$ confidence interval, 1.97 7.94), but the use of a short-term mechanical circulatory support was not $(P=.937)$.

Conclusions: Short-term mechanical circulatory support can optimize patients in refractory cardiogenic shock and serve as a bridge to implantation of a durable left ventricular assist device. However, the early mortality rate after durable left ventricular assist device implantation is high because of unrecognized right ventricular failure. ( $\mathrm{J}$ Thorac Cardiovasc Surg 2017;153:752-62)

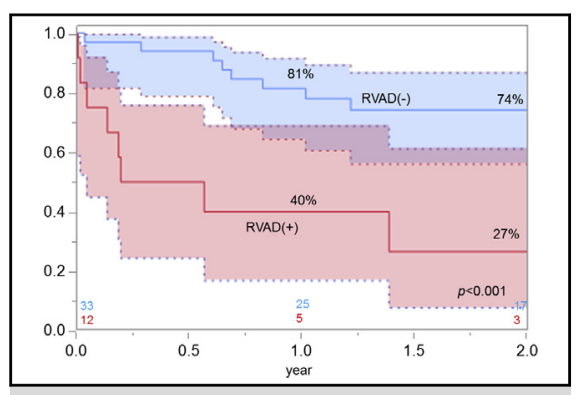

Short-term mechanical circulatory support can serve a bridge to durable LVAD therapy.

\section{Central Message}

ST-MCS can optimize patients in refractory cardiogenic shock and serve as a bridge to durable LVAD. However, the early mortality rate after durable LVAD implantation is high because of unrecognized right ventricular failure.

\section{Perspective}

No established guidelines exist on the approach before durable LVAD implantation for patients in refractory cardiogenic shock. This study shows the usefulness of ST-MCS as BTB therapy for patients in refractory cardiogenic shock at a single high-volume center. The results will allow better strategy in selection and treatment for patients in cardiogenic shock.

See Editorial Commentary page 763.
From the Divisions of ${ }^{\mathrm{a} C}$ Cardiothoracic Surgery and ${ }^{\mathrm{b}}$ Cardiology, Columbia University Medical Center, New York, NY.

Read at the 96th Annual Meeting of The American Association for Thoracic Surgery, May 14-18, 2016, Baltimore, Maryland.

Received for publication May 27, 2016; revisions received Sept 27, 2016; accepted for publication Oct 20, 2016; available ahead of print Dec 14, 2016.

Address for reprints: Koji Takeda, MD, PhD, 177 Ft Washington Ave, New York, NY 10032 (E-mail: kt2485@cumc.columbia.edu).

$0022-5223 / \$ 36.00$

Copyright $(\odot 2016$ by The American Association for Thoracic Surgery

http://dx.doi.org/10.1016/j.jtcvs.2016.10.085
Left ventricular assist devices (LVADs) have become the standard of care for patients with end-stage heart failure as a bridge to transplant therapy and as a destination

Scanning this QR code will take you to supplemental figures and tables for this article. 


\section{Abbreviations and Acronyms \\ BTB = bridge-to-bridge \\ ECMO = extracorporeal membrane oxygenation \\ HMRS $=$ HeartMate II Risk Score \\ INR $=$ international normalized ratio \\ INTERMACS $=$ Interagency Registry for Mechanically Assisted Circulatory Support \\ $\mathrm{LV} \quad=$ left ventricular \\ LVAD $\quad=$ left ventricular assist device \\ MELD $\quad=$ Model for End-Stage Liver Disease \\ RVAD $=$ right ventricular assist device \\ ST-MCS = short-term mechanical circulatory support}

therapy. ${ }^{1-3}$ The 7 th annual Interagency Registry for Mechanically Assisted Circulatory Support (INTERMACS) report stated that approximately $15 \%$ of all patients underwent LVAD implantation in an INTERMACS profile I; this rate has not changed in the past several years. ${ }^{4}$ Despite improving overall outcomes, worse outcomes of patients with an INTERMACS profile I have been reported compared with those of patients with other profiles. ${ }^{4}$

The major problems of patients with refractory cardiogenic shock and an INTERMACS profile I include not only collapsed hemodynamics but also other end-organ dysfunction or uncertified neurologic status. At the first encounter with patients in cardiogenic shock, the candidacy for destination therapy or bridge-to-transplant LVAD often is unclear. In addition, because of the acuity of the illness, the time available to make a decision is limited. Therefore, an alternative approach instead of primary implantable LVAD insertion can be considered using short-term mechanical circulatory support (ST-MCS) for patients with refractory cardiogenic shock. This treatment strategy is considered bridge-to-bridge (BTB) therapy. ${ }^{5-7}$ The advantage of this strategy is that hemodynamic stability and end-organ function improvement can be achieved before long-term durable LVAD implantation. ${ }^{5}$ However, little data exist on the outcomes of the bridge to durable LVAD strategy in the population receiving BTB therapy. The purpose of this study was to elucidate the short- and midterm outcomes in patients receiving BTB therapy.

\section{MATERIALS AND METHODS \\ Patient Selection}

The Columbia University Medical Center Institutional Review Board approved this study. A total of 382 patients who received continuous-flow LVADs between March 2004 and December 2014 at the Columbia University Medical Center were retrospectively reviewed. Of these patients, $45(12 \%)$ received ST-MCS for refractory cardiogenic shock before undergoing durable LVAD implantation surgery (BTB group). We analyzed the clinical results of these 45 patients.

\section{Strategy for Patients in Refractory Cardiogenic Shock}

Our strategy for patients in refractory cardiogenic shock is shown in Figure E1. In general, all patients in refractory cardiogenic shock received ST-MCS devices to stabilize and optimize their condition during this study period. Refractory cardiogenic shock is characterized by a systolic blood pressure less than $90 \mathrm{~mm} \mathrm{Hg}$, cardiac index less than $2.0 \mathrm{~L} / \mathrm{min} / \mathrm{m}^{2}$, pulmonary capillary wedge pressure greater than $16 \mathrm{~mm} \mathrm{Hg}$ on adequate inotropes (or evidence of pulmonary edema in the absence of a pulmonary artery catheter), and evidence of end-organ failure or the inability to be weaned from cardiopulmonary bypass for postcardiotomy shock. These patients are rapidly evaluated by our multidisciplinary "Shock Team," which consists of cardiac surgeons, interventional and heart failure cardiologists, nurse practitioners, and intensive care physicians, to determine the most suitable ST-MCS device for each patient. We prefer to use a CentriMag (Thoratec Corp, Pleasanton, Calif) ventricular assist device or venoarterial extracorporeal membrane oxygenation (ECMO) ${ }^{7,8}$ During this study period, other percutaneous devices such as the Impella (Abiomed Inc, Danvers, Mass) and the TandemHeart (CardiacAssist Inc, Pittsburgh, Pa) were used in the catheterization laboratory because of sudden hemodynamic collapse during the interventional procedure or used in other hospitals.

\section{Indication and Surgical Technique of Extracorporeal Membrane Oxygenation and CentriMag Device}

The indication and implantation technique for ECMO and CentriMag device have been reported. ${ }^{7,8}$ ECMO is chosen when a patient has unclear neurologic status, has hemodynamics too unstable to allow a safe transfer to the operating room, has developed severe coagulopathy because of shock liver with a sudden and marked elevation in liver enzyme levels, or has received antiplatelet therapy before percutaneous coronary intervention. Depending on the clinical status of the patient, the ECMO device is placed at the bedside, at the catheterization laboratory, or in the operating room by surgeons. Femoral access is the first choice for peripheral cannulation. The ECMO circuit consists of a Quadrox D oxygenator (Maquet, Wayne, NJ), Rotaflow (Maquet), and SMARTcoated tubing (Sorin, Milan, Italy). Biomedicus femoral cannulas (Medtronic, Minneapolis, Minn) are used. Arterial cannula sizes of $15 \mathrm{~F}$ to $23 \mathrm{~F}$ and venous cannula sizes of $19 \mathrm{~F}$ to $25 \mathrm{~F}$ are used. A distal perfusion cannula is selectively inserted through a cut-down to the superficial femoral artery whenever there is the lack of a strong Doppler signal on the ipsilateral foot.

During this study period, the standard surgical approach for CentriMag device implantation was through a sternotomy using cardiopulmonary bypass. Biventricular support was an essential configuration for patients in cardiogenic shock. Double purse-string sutures with 2-0 or 3-0 polypropylene buttressed with bovine pericardial pledgets were placed at the cannulation sites and passed through DLP tourniquets (Medtronic, Inc). For the LVAD, the inflow cannula $(28 \mathrm{~F}-40 \mathrm{~F})$ was inserted into the left ventricular (LV) apex. An 8- or 10-mm Dacron graft was sewn onto the ascending aorta. The outflow cannula (18F-24F) was inserted through the graft and secured with silk ties. For the right ventricular assist device (RVAD), the inflow cannula $(28 \mathrm{~F}-31 \mathrm{~F})$ was inserted into the right atrium, and the outflow cannula (18F-24F) was inserted into the main pulmonary artery. The cannulas were secured to the tourniquets with 0 silk ties. These tourniquets were folded and tied with another 0 silk tie onto the cannula at their entry point to the posterior aspect of the rectus abdominis muscle fascia, which prevented cannula dislodgement and allowed ambulatory rehabilitation.

Anticoagulation with intravenous heparin is initiated at the rate of 300 $\mathrm{U} / \mathrm{h}$ once coagulopathy is reversed or the chest tube drainage becomes 
serosanguinous. A partial thrombin time is measured every 8 hours. Heparin dose is titrating up gradually and maintained throughout the support with a goal partial thrombin time of 60 to 80 seconds.

\section{Bridge to Decision}

While supported by the device, patients are managed by the multidisciplinary Heart Team and undergo evaluation for heart transplantation or durable LVAD as destination therapy. If patients show sustained shock and end-organ dysfunction after percutaneous ST-MCS support, they are converted to CentriMag device support to obtain more powerful and durable support. In our current strategy, we maximize the benefit of ST-MCS to optimize clinical conditions as much as possible. Once the general condition of patients improves, including hemodynamics, neurologic function, and end-organ function, myocardial function is evaluated by device weaning. The weaning study generally is performed in the intensive care unit under monitoring with a Swan-Ganz catheter and echocardiography. According to the weaning test results, the ST-MCS device is explanted to one of the following destinations: exchange to durable LVAD, explantation for myocardial recovery, or explantation for heart transplantation. ${ }^{7}$ If a patient shows no sign of LV recovery and satisfies the criteria for a durable LVAD as a bridge to transplant or destination therapy, ST-MCS is converted to a durable LVAD.

In patients with a CentriMag biventricular assist device, an RVAD weaning study was performed. With adequate heparinization, RVAD flow was decreased by $0.5 \mathrm{~L}$ every 1 minute to a $1 \mathrm{~L} / \mathrm{min}$ flow. Adding new vasoactive drugs or nitric oxide inhalation to facilitate weaning was generally not recommended. Maintenance of central venous pressure less than $13 \mathrm{~mm} \mathrm{Hg}$, stable mean arterial pressure $(>60 \mathrm{~mm} \mathrm{Hg})$, and stable LVAD flow ensured sufficient right ventricular function. ${ }^{7}$ Patients who passed the RVAD weaning test proceeded to conversion to durable LVAD.

\section{Left Ventricular Assist Device Implant Procedures and Concomitant Procedures}

During this study period, the HeartMate II (Thoratec Corp) was chosen for all patients receiving destination therapy. For patients receiving a bridge to transplant, the HeartMate II or HeartWare (HeartWare Corp, Framingham, Mass) was selected according to patients' or health care proxys' request. In patients with preoperative CentriMag device support, inflow and outflow cannulae are removed after the establishment of cardiopulmonary bypass. The LVAD implant procedures are conducted as previously reported. ${ }^{9}$ In patients with mild or greater aortic insufficiency, aortic valve repair or replacement with a tissue valve was performed. In most cases, the aortic valve was repaired by approximating the raphe of each leaflet. Mitral valve repair was performed in patients with severe functional mitral regurgitation at the surgeon's discretion. The tricuspid valve procedure generally was performed in cases of moderate or greater tricuspid regurgitation. Tricuspid valve annuloplasty with an annuloplasty ring is the firstchoice procedure. In the case of severe leaflet tethering or destruction, tricuspid replacement is performed with a bioprosthetic valve. The decision regarding concomitant RVAD insertion is made individually for each patient at the surgeon's discretion.

\section{Postdurable Left Ventricular Assist Device Management}

After device implantation, all patients received a standardized heart failure medical regimen, including neurohormonal antagonists, diuretics, and antiarrhythmic agents as needed. Antiplatelet and anticoagulation therapy with aspirin and warfarin are implemented once adequate hemostasis has been achieved. Patients receive follow-up at 1 week after the initial discharge and monthly thereafter unless an issue necessitated more frequent visits. Clinic visit frequency varies among patients depending on individual medical issues and travel distances.

\section{Data Collection}

Patient data were obtained from electronic medical records. Primary outcome variables included in-hospital mortality and 2-year overall survival. Preoperative variables that may affect the primary outcome were identified, including baseline demographics, medical histories, laboratory values, and hemodynamics. Intraoperative variables were collected, such as cardiopulmonary bypass time, amount of blood products used, and concomitant cardiac procedures. Early postimplantation data included complications occurring between the operation and the hospital discharge. Major adverse events requiring readmission during LVAD support were recorded. These included right heart failure, major bleeding events such as gastrointestinal tract bleeding and significant epistaxis, major cerebral events, cardiac arrhythmia, and infections related or unrelated to the device. Follow-up data were collected for a period of 0 to 6.6 years (mean, 2.21 years; median, 1.28 years; interquartile range, $0.58-3.8$ years). Follow-up was complete in $95 \%$ of cases as of December 31, 2015. The HeartMate II Risk Score (HMRS) was calculated as follows: HMRS $=0.0274 \times$ age $-0.723 \times$ serum albumin $(\mathrm{mg} / \mathrm{dL})-0.74 \times$ serum creatinine $(\mathrm{mg} / \mathrm{dL})+1.136 \times$ international normalized ratio (INR). ${ }^{10}$ The estimated glomerular filtration rate was calculated using the following formula: estimated glomerular filtration rate $=186 \times($ serum creatinine $/ 88.4)-1.154 \times($ age $)-0.203 \times(0.742$ if female $) \times(1.210$ if black). The Model for End-Stage Liver Disease Score (MELD) was calculated using the following formula: MELD score $=10 \times((0.957 \times \ln$ $($ serum creatinine $))+(0.378 \times \ln ($ serum bilirubin $))+(1.12 \times \ln$ $($ INR)) $)+6.43$.

\section{Statistical Analysis}

All data were analyzed using SPSS software version 11.0 (SPSS, Inc, Chicago, Ill). Statistical significance was determined on the basis of a predetermined $\alpha=0.05$. Categoric variables were summarized with frequencies and percentages and compared across groups using chi-square or Fisher exact tests. Continuous variables are summarized as mean \pm standard deviation or median (interquartile range). Two-sample $t$ tests, Mann-Whitney $U$ test, or paired t test was used for comparisons across groups. Overall survival was estimated using Kaplan-Meier curves and compared across groups using log-rank tests. Multivariable logistic regression models were used to identify the risk factors for in-hospital mortality. Cox regression hazard models for survival outcomes were used to adjust for the effects of preoperative variables on midterm survival. In both regression models, variables included in the univariate analysis are detailed in Table E1. The factors in univariate analysis with $P$ less than .10 were considered for a multivariate logistic regression or Cox hazard model to identify the risk factors. In the multivariate logistic regression model for in-hospital mortality, we enrolled the 3 most clinically important parameters (use of ST-MCS, use of postoperative RVAD, and hemoglobin level) because there were only 27 (7\%) mortalities. For the Cox regression hazard model, we included 10 parameters: age, use of ST-MCS, redo, hemoglobin, creatinine, albumin, cardiopulmonary bypass time, red blood cell transfusion, fresh-frozen plasma, and use of postoperative RVAD. The percentage of patients who had missing values in the risk analysis was less than $2 \%$, and they were excluded from the multivariate analysis.

\section{RESULTS \\ Short-Term Mechanical Circulatory Support Used and Effect of Short-Term Mechanical Circulatory Support on Refractory Cardiogenic Shock}

The ST-MCS devices used in 45 patients as BTB therapy are summarized in Figure 1. For initial support, 21 patients $(47 \%)$ underwent CentriMag ventricular assist 


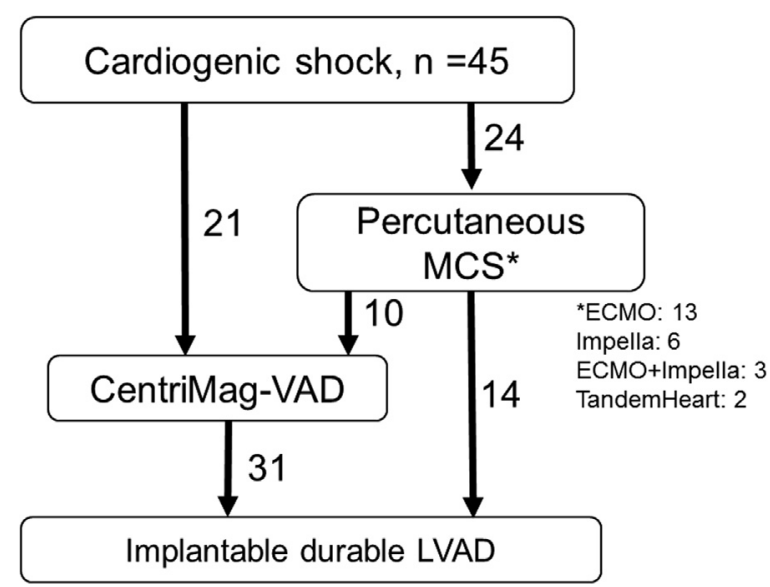

FIGURE 1. The ST-MCS devices used in 45 patients as BTB therapy are summarized. MCS, Mechanical circulatory support; ECMO, extracorporeal membrane oxygenation; $V A D$, ventricular assist device; $L V A D$, left ventricular assist device.

device insertion. Twenty-four patients $(53 \%)$ received a percutaneous device as an initial support. Of these, 14 patients ( 7 with ECMO, 5 with Impella, 1 with ECMO and Impella, 1 with TandemHeart) underwent primary conversion to durable LVAD. Ten patients (6 with ECMO, 1 with Impella, 2 with ECMO and Impella, 1 with TamdemHeart) required further optimization with the CentriMag biventricular assist device because of sustained shock and end-organ dysfunction. In total, 31 patients had CentriMag device support before durable LVAD insertion.

Table 1 shows the patients' characteristics before receiving ST-MCS. Patients had high filling pressure with a low mixed venous saturation level and elevated serum lactate level. The renal and hepatic functions were severely impaired. The calculated HMRS and MELD score were $2.58 \pm 1.76$ and $18.6 \pm 8.5$, respectively. Patients who received a percutaneous device as initial support were more likely to be intubated and to have cardiopulmonary resuscitation at the time of insertion.

The median ST-MCS duration was 14.0 (7.5-29.5) days. The change of end-organ function from before to after ST-MCS (before durable LVAD implantation) is shown in Table 2. Renal function remarkably improved after ST-MCS support, but the serum albumin level significantly decreased. The calculated MELD score and HMRS showed significant improvement during STMCS support. Subgroup comparison according to the type of ST-MCS at the time of durable LVAD implant is listed in Table 2. Hepatic function including transaminase and total bilirubin tended to be more normalized in patients with CentriMag device support. The MELD score was significantly higher in patients with a percutaneous device.

\section{Baseline Comparison Between the Bridge-to-Bridge Group and Primary Durable Left Ventricular Assist Device Group}

Baseline characteristics before conversion to durable LVAD in the BTB group were compared with those of 337 patients who underwent primary durable LVAD implantation without bridge (nonbridging group) (Table E2). Patients in the BTB group were significantly younger. The nonbridging group had more nonischemic causes. The central venous pressure, mean pulmonary artery, and pulmonary capillary wedge pressure were significantly lower in the BTB group. Preoperative renal function was significantly better in the BTB group, whereas hepatic function was better in the nonbridging group. The calculated HMRS was similar between the 2 groups.

\section{Intraoperative and Early Postoperative Outcomes}

Intraoperative and early postoperative outcomes are summarized in Table 3. Most patients $(91 \%)$ received the HeartMate II device. Of note, the incidence of postoperative RVAD placement was high, up to $27 \%$. In-hospital mortality was $18 \%$. The outcome comparison between 14 patients with percutaneous device and 31 patients with CentriMag device support before conversion to durable LVAD is outlined in Table 3. Patients with CentriMag device support had longer support duration than patients with a percutaneous device. The incidence of postoperative RVAD use and in-hospital mortality was higher in patients with percutaneous devices compared with patients with the CentriMag device, although the differences did not reach statistical significance.

In the entire cohort of 382 patients, $27(7 \%)$ died during index hospitalization. Multivariable logistic regression analysis for in-hospital mortality in the entire cohort revealed that low hemoglobin levels (odds ratio, 0.67; $P=.002 ; 95 \%$ confidence interval, $0.50-0.87)$ and the use of postoperative RVAD (odds ratio, 15.4; $P=.001$; 95\% confidence interval, 5.77-42.2) were independent risk factors for in-hospital mortality. The use of ST-MCS was not a predictor for in-hospital mortality (odds ratio, $1.22, P=.744 ; 95 \%$ confidence interval, 0.39-4.19).

\section{Midterm Outcomes}

Of 37 patients who were discharged, 6 died during the 2year follow-up. The cause of death was stroke in 1 patient, sepsis in 1 patient, pump failure in 1 patient, malignancy in 1 patient, and others in 2 patients. Nineteen patients $(42 \%)$ successfully bridged to heart transplantation and 6 patients $(13 \%)$ underwent LVAD explantation because of native heart function recovery within 2 years. The cause of cardiogenic shock in 6 patients who experienced myocardial recovery was fulminant myocarditis in 2 , postcardiotomy shock in 2 , acute myocardial infarction in 1 , and acute 
TABLE 1. Before short-term mechanical circulatory support characteristics

\begin{tabular}{|c|c|c|c|c|}
\hline & \multirow[b]{2}{*}{ All $(\mathrm{N}=45)$} & \multicolumn{2}{|c|}{ Type of initial ST-MCS } & \multirow[b]{2}{*}{$P$ value } \\
\hline & & Percutaneous device $(n=24)$ & $\begin{array}{l}\text { CentriMag (Thoratec Corp, } \\
\text { Pleasanton, Calif) }(\mathbf{n}=\mathbf{2 1})\end{array}$ & \\
\hline Age (y) & $53 \pm 10$ & $55 \pm 9$ & $52 \pm 12$ & .296 \\
\hline Male, n (\%) & $39(87)$ & $21(88)$ & $18(86)$ & $>.999$ \\
\hline $\operatorname{BSA}\left(\mathrm{m}^{2}\right)$ & $2.00 \pm 0.29$ & $2.02 \pm 0.26$ & $1.98 \pm 0.32$ & .667 \\
\hline BMI $\left(\mathrm{kg} / \mathrm{m}^{2}\right)$ & $26.5 \pm 8.5$ & $26.8 \pm 9.7$ & $26.2 \pm 7.3$ & .854 \\
\hline Cause & & & & .332 \\
\hline AMI, n (\%) & $20(44)$ & $13(54)$ & $7(33)$ & \\
\hline ADHF, n (\%) & $18(40)$ & $9(38)$ & $9(43)$ & \\
\hline Postcardiotomy, n (\%) & $5(11)$ & $1(4)$ & $4(19)$ & \\
\hline Myocarditis, n (\%) & $2(4)$ & $1(4)$ & $1(5)$ & \\
\hline $\mathrm{DM}, \mathrm{n}(\%)$ & $15(33)$ & $7(29)$ & $8(38)$ & .546 \\
\hline HT, n (\%) & $27(60)$ & $16(67)$ & $11(52)$ & .374 \\
\hline PVD, n (\%) & $6(13)$ & $4(17)$ & $2(10)$ & .670 \\
\hline COPD, n (\%) & $5(11)$ & $4(17)$ & $1(5)$ & .352 \\
\hline CVA, n $(\%)$ & $4(9)$ & $3(13)$ & $1(5)$ & .363 \\
\hline Inotropes, $\mathrm{n}(\%)$ & $40(89)$ & $22(92)$ & $18(86)$ & .652 \\
\hline Pressor, n (\%) & $33(73)$ & $18(75)$ & $15(71)$ & $>.999$ \\
\hline IABP, n $(\%)$ & $29(64)$ & $12(50)$ & $17(81)$ & .060 \\
\hline Intubation, $\mathrm{n}(\%)$ & $29(64)$ & $19(79)$ & $10(48)$ & .035 \\
\hline Ongoing CPR, n (\%) & $6(13)$ & $6(25)$ & $0(0)$ & .023 \\
\hline CVVHD, n $(\%)$ & $4(9)$ & $1(4)$ & $3(14)$ & .326 \\
\hline CVP (mm Hg) & $15.7 \pm 7.0$ & $13.8 \pm 6.6$ & $17.3 \pm 7.2$ & .180 \\
\hline mPAP (mm Hg) & $34.3 \pm 9.0$ & $36.6 \pm 10.5$ & $32.8 \pm 7.5$ & .262 \\
\hline Lactate $(\mathrm{mmol} / \mathrm{L})$ & $4.2 \pm 2.5$ & $4.4 \pm 2.5$ & $4.1 \pm 2.6$ & .799 \\
\hline Mixed venous oxygen saturation (\%) & $44.8 \pm 12.3$ & $45.5 \pm 15.0$ & $43.9 \pm 8.5$ & .756 \\
\hline AST (IU/dL) & $60(30-226)$ & $114(30-256)$ & $54(33-204)$ & .508 \\
\hline ALT (IU/dL) & $45(23-195)$ & $40(19-195)$ & $48(24-195)$ & .508 \\
\hline T-bil (mg/dL) & $1.4(1.1-2.8)$ & $1.6(1.2-4.6)$ & $1.3(0.9-2.8)$ & .292 \\
\hline Albumin (mg/dL) & $3.27 \pm 0.55$ & $3.37 \pm 0.47$ & $3.20 \pm 0.61$ & .351 \\
\hline BUN (mg/dL) & $41.4 \pm 21.8$ & $41.4 \pm 17.2$ & $41.4 \pm 28.3$ & .994 \\
\hline Creatinine (mg/dL) & $1.76 \pm 0.84$ & $1.64 \pm 0.53$ & $1.86 \pm 1.01$ & .433 \\
\hline $\mathrm{eGFR}\left(\mathrm{mL} / \mathrm{min} / 1.73 \mathrm{~m}^{2}\right)$ & $53.9 \pm 27.5$ & $52.7 \pm 23.3$ & $54.8 \pm 30.7$ & .823 \\
\hline INR & $1.90 \pm 1.34$ & $2.23 \pm 1.77$ & $1.58 \pm 0.64$ & .141 \\
\hline WBC $\left(\times 1000\right.$ counts $\left./ \mathrm{mm}^{3}\right)$ & $14.2 \pm 5.68$ & $15.0 \pm 5.57$ & $13.5 \pm 5.87$ & .421 \\
\hline MELD score & $18.6 \pm 8.5$ & $18.7 \pm 10.8$ & $17.8 \pm 6.1$ & .760 \\
\hline HMRS & $2.58 \pm 1.76$ & $3.00 \pm 2.27$ & $2.26 \pm 1.19$ & .360 \\
\hline
\end{tabular}

$S T-M C S$, Short-term mechanical circulatory support; $B S A$, body surface area; $B M I$, body mass index; $A M I$, acute myocardial infarction; $A D H F$, acute decompensating heart failure; $D M$, diabetes mellitus; $H T$, hypertension; $P V D$, peripheral vascular disease; $C O P D$, chronic obstructive pulmonary disease; $C V A$, cerebrovascular accident; $I A B P$, intra-aortic balloon pumping; $C P R$, cardiopulmonary resuscitation; $C V V H D$, continuous veno-venous hemodialysis; $C V P$, central venous pressure; $m P A P$, mean pulmonary arterial pressure; $A S T$, aspartate transaminase; $A L T$, alanine transaminase; T-bil, total bilirubin; $B U N$, blood urea nitrogen; $e G F R$, estimated glomerular filtration rate; INR, international normalization ratio; $W B C$, white blood cell count; $M E L D$, Model for End-Stage Liver Disease; HMRS, HeartMate Risk Score.

decompensating heart failure in 1 . Competing outcomes depiction in the BTB group are shown in Figure 2.

The overall survival of patients in the BTB group is shown in Figure 3. Overall survival was $70 \%$ and $62 \%$ at 1 and 2 years, respectively. The 2-year overall survival was similar between patients who received the percutaneous ST-MCS $(\mathrm{n}=14)$ and patients who received the CentriMag device $(\mathrm{n}=31)$ before conversion to durable LVAD (56\% vs $66 \%, P=.306)$. The Kaplan-Meier curve stratified by RVAD use is shown in Figure 4. Patients who required RVAD had worse survival than those without RVAD.
Early and late outcomes in the BTB group were compared with the nonbridging population (Table E3). The overall survival, overall survival after the initial discharge, and overall survival in patients who did not require RVAD support between groups are shown in Figure E2, A-C. The BTB groups had worse early and late outcomes compared with the nonbridging population. The overall survival at 2 years was significantly worse in the BTB group ( $62 \%$ vs $80 \%, P=.009)$. However, the overall survival of patients who could be discharged after durable LVAD implantation was similar between the 2 groups $(81 \%$ vs $88 \%, P=.501)$. Likewise, if patients did not 
TABLE 2. End-organ function before and after short-term mechanical circulatory support

\begin{tabular}{|c|c|c|c|c|c|c|}
\hline & \multirow{2}{*}{$\begin{array}{c}\text { Before ST-MCS } \\
\text { All }(\mathrm{N}=45) \\
\end{array}$} & \multicolumn{5}{|c|}{ After ST-MCS } \\
\hline & & All $(N=45)$ & $P$ value* & $\begin{array}{c}\text { Percutaneous } \\
\text { device }(n=14)\end{array}$ & CentriMag $(\mathbf{n}=\mathbf{3 1})$ & $P$ value \\
\hline AST (IU/dL) & $60(30-226)$ & $24(18-35)$ & .122 & $78(32-239)$ & $29(21-72)$ & .021 \\
\hline ALT (IU/dL) & $45(23-195)$ & $22(15-40)$ & .133 & $29(20-153)$ & $21(16-76)$ & .099 \\
\hline T-bil (mg/dL) & $1.4(1.1-2.8)$ & $1.1(0.7-1.9)$ & .218 & $1.9(1.2-4.4)$ & $1.0(0.5-2.1)$ & .078 \\
\hline Albumin $(\mathrm{mg} / \mathrm{dL})$ & $3.27 \pm 0.55$ & $3.11 \pm 0.55$ & .017 & $3.09 \pm 0.60$ & $3.11 \pm 0.53$ & .908 \\
\hline BUN (mg/dL) & $41.4 \pm 21.8$ & $22.6 \pm 12.1$ & $<.001$ & $26.8 \pm 12.5$ & $20.8 \pm 11.7$ & .140 \\
\hline Creatinine (mg/dL) & $1.76 \pm 0.84$ & $1.15 \pm 0.57$ & $<.001$ & $1.23 \pm 0.59$ & $1.11 \pm 0.56$ & .526 \\
\hline $\mathrm{eGFR}\left(\mathrm{mL} / \mathrm{min} / 1.73 \mathrm{~m}^{2}\right)$ & $53.9 \pm 27.5$ & $92.6 \pm 52.7$ & $<.001$ & $87.9 \pm 54.5$ & $94.5 \pm 52.7$ & .713 \\
\hline WBC $\left(\times 1000\right.$ counts $\left./ \mathrm{mm}^{3}\right)$ & $14.2 \pm 5.68$ & $12.2 \pm 3.79$ & .075 & $12.3 \pm 1.98$ & $12.1 \pm 4.40$ & .886 \\
\hline MELD score & $18.6 \pm 8.5$ & $11.2 \pm 6.1$ & .001 & $14.2 \pm 7.0$ & $9.5 \pm 5.0$ & .028 \\
\hline HMRS & $2.58 \pm 1.76$ & $1.60 \pm 0.89$ & .006 & $1.86 \pm 0.25$ & $1.44 \pm 0.18$ & .189 \\
\hline
\end{tabular}

ST-MCS, Short-term mechanical circulatory support; AST, aspartate transaminase; ALT, alanine transaminase; T-bil, total bilirubin; BUN, blood urea nitrogen; $e G F R$, estimated glomerular filtration rate; $W B C$, white blood cell count; MELD, Model for End-Stage Liver Disease; HMRS, HeartMate Risk Score. *Before ST-MCS all versus after ST-MCS all. $\dagger$ Percutaneous device versus CentriMag.

require postoperative RVAD, overall survival at 2 years was $80 \%$ in the nonbridging group and $74 \%$ in the BTB group $(P=.793)$.

In the entire cohort of 382 patients, $113(30 \%)$ died during the follow-up period of this study. The Cox proportional hazard analysis in the entire cohort was performed to elucidate the risk factors for overall death during midterm LVAD support (Table E4). In this analysis, older age, higher preoperative serum creatinine, more red blood cell product transfusions, and postoperative temporary RVAD were

TABLE 3. Perioperative variables and postoperative outcomes

\begin{tabular}{|c|c|c|c|c|}
\hline & \multirow[b]{2}{*}{ All $(\mathbf{N}=\mathbf{4 5})$} & \multicolumn{2}{|c|}{ Type of ST-MCS before durable LVAD } & \multirow[b]{2}{*}{$P$ value } \\
\hline & & Percutaneous device $(n=14)$ & CentriMag $(\mathbf{n}=\mathbf{3 1})$ & \\
\hline Duration of ST-MCS (d) & $14(7.5-29.5)$ & $5.5(3-12)$ & $20(13-33)$ & $<.001$ \\
\hline Durable LVAD & & & & .294 \\
\hline HeartMate II (Thoratec Corp, Pleasanton, Calif), n (\%) & $41(91)$ & $14(100)$ & $27(87)$ & \\
\hline HeartWare (HeartWare Corp, Framingham, Mass), n (\%) & $4(9)$ & $0(0)$ & $4(13)$ & \\
\hline \multicolumn{5}{|l|}{ Concomitant valve surgery } \\
\hline Aortic valve surgery, n (\%) & $10(22)$ & $2(14)$ & $8(26)$ & .469 \\
\hline Mitral valve surgery, n (\%) & $5(11)$ & $3(21)$ & $2(6)$ & .166 \\
\hline Tricuspid valve surgery, n ( $\%)$ & $8(18)$ & $3(21)$ & $5(16)$ & .689 \\
\hline Redo sternotomy, n (\%) & $35(78)$ & $4(29)$ & $31(100)$ & $<.001$ \\
\hline \multicolumn{5}{|l|}{ Transfusion } \\
\hline Packed red blood cell (units) & $5.0 \pm 3.2$ & $4.8 \pm 3.4$ & $5.1 \pm 3.2$ & .756 \\
\hline Fresh-frozen plasma (units) & $5.8 \pm 3.7$ & $5.2 \pm 4.8$ & $6.0 \pm 3.1$ & .751 \\
\hline Platelets (units) & $15.8 \pm 8.4$ & $13.0 \pm 9.5$ & $16.9 \pm 7.8$ & .179 \\
\hline CPB time (min) & $139 \pm 57$ & $150 \pm 89$ & $134 \pm 35$ & .410 \\
\hline ICU stay $(d)$ & $13(8-30)$ & $16.5(11-34)$ & $12(7-28)$ & .551 \\
\hline Hospital stay (d) & $41(23-65)$ & $49.5(26-65)$ & $33(22-67)$ & .863 \\
\hline Postoperative RVAD, n (\%) & $12(27)$ & $6(43)$ & $6(19)$ & .147 \\
\hline CentriMag RVAD & 11 & 6 & 5 & \\
\hline Percutaneous RVAD & 1 & 0 & 1 & \\
\hline \multicolumn{5}{|l|}{ Perioperative complication, $\mathrm{n}(\%)$} \\
\hline Requirement of reexploration & $15(33)$ & $5(36)$ & $10(32)$ & $>.999$ \\
\hline Ventricular arrhythmia & $9(20)$ & $3(21)$ & $6(19)$ & $>.999$ \\
\hline Atrial fibrillation & $10(22)$ & $3(21)$ & $7(23)$ & $>.999$ \\
\hline Sepsis/bacteremia & $10(22)$ & $3(21)$ & $7(23)$ & $>.999$ \\
\hline Stroke & 7 (16) & $3(21)$ & $4(13)$ & .659 \\
\hline CVVHD & $11(24)$ & $3(21)$ & $8(26)$ & $>.999$ \\
\hline In-hospital mortality, n (\%) & $8(18)$ & $4(29)$ & $4(13)$ & .232 \\
\hline
\end{tabular}

ST-MCS, Short term mechanical circulatory support; $L V A D$, left ventricular assist device; $C P B$, cardiopulmonary bypass; $I C U$, intensive care unit; $R V A D$, right ventricular assist device; $C V V H D$, continuous veno-venous hemodialysis. 


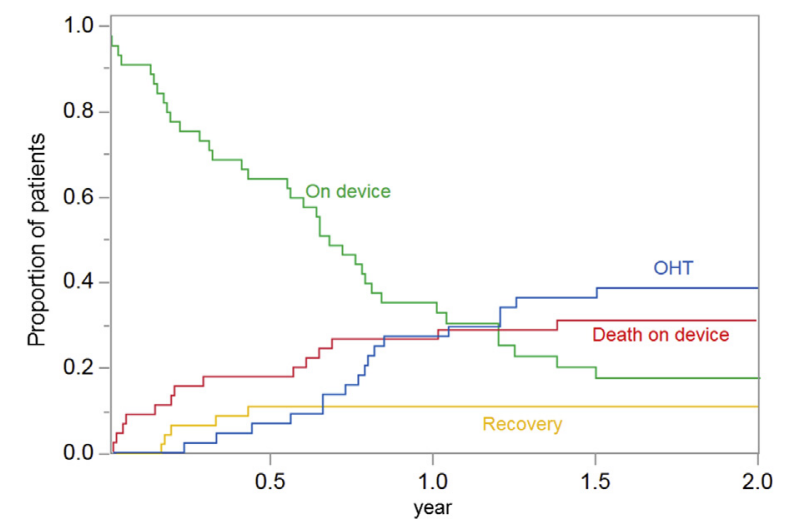

FIGURE 2. Competing analysis curve in BTB cases $(\mathrm{n}=45)$. OHT, Orthotropic heart transplantation.

independent risk factors. The use of ST-MCS was not a risk factor for overall mortality.

\section{Outcomes Stratified by Right Ventricular Assist Device Use}

Because the use of an RVAD was a significant independent predictor for early and late death, we performed a subgroup analysis according to RVAD use. We compared baseline parameters in BTB cases according to the postoperative RVAD requirement (Table 4). Compared with patients who did not require an RVAD, patients who did receive an RVAD were more likely to have a larger body surface area and body mass index, higher central venous pressure and serum bilirubin level before ST-MCS, and higher serum potassium and INR levels before durable LVAD implantation.

\section{DISCUSSION}

The primary findings of this study are as follows: (1) ST-MCS could optimize end-organ function and hemodynamics and serve as a bridge to durable LVAD in patients

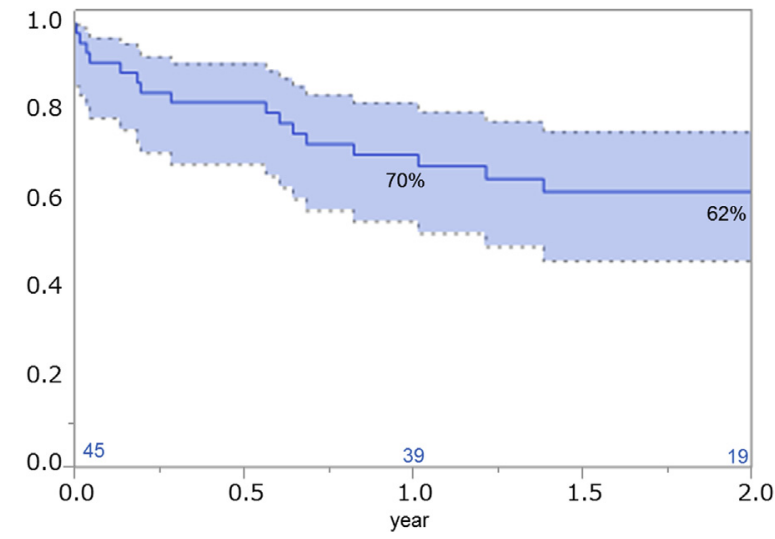

FIGURE 3. Kaplan-Meier survival curves showing overall 2-year survival in BTB cases.

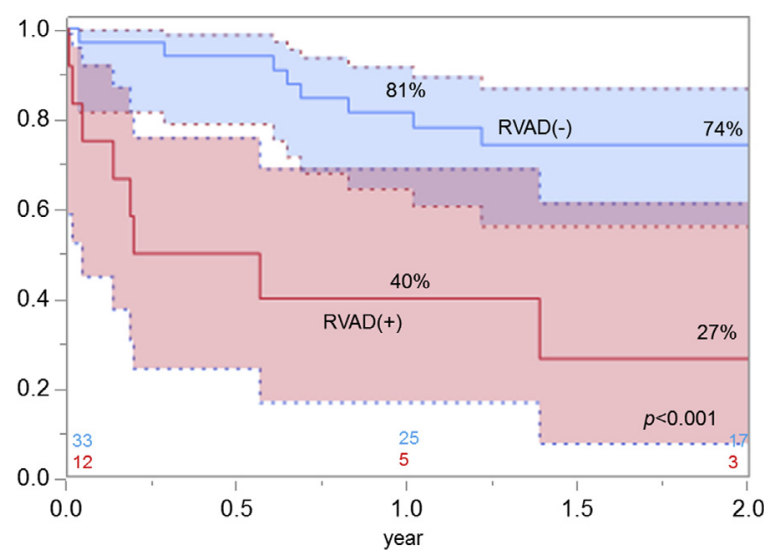

FIGURE 4. Kaplan-Meier curve of overall survival stratified by postoperative RVAD use. RVAD, Right ventricular assist device.

in refractory cardiogenic shock; (2) despite optimization, outcomes in BTB cases were not satisfactory because of severe right heart failure after conversion to durable LVAD; (3) midterm survival in the BTB cases was comparable to that in the nonbridging population if patients did not require an RVAD; and (5) the use of ST-MCS was not a predictor for early or late mortality.

Patients with an INTERMACS profile I classification are defined as "crashing and burning" subjects with cardiogenic shock that is refractory to inotropes. However, the INTERMACS classification only provides a snapshot of hemodynamic status and does not necessarily discriminate between patients with preserved end-organ function and those with advanced end-organ dysfunction. In-hospital mortality in this subgroup remains high, and current recommendations are unclear about the utility of primary durable LVAD implantation. ${ }^{4,11}$ Adamo and colleagues ${ }^{12}$ reported that 90-day mortality of durable LVAD implantation for patients with an INTERMACS profile I was $6.95 \%$ to $39 \%$ depending on the preoperative HMRS. This study suggested that the INTERMACS profile I includes a wide range of population according to their status except for the hemodynamic condition. Our BTB cases presented with refractory cardiogenic shock and severe end-organ dysfunction. The HMRS before ST-MCS was 2.6 (high-risk group). Our patients seemed to be an extremely high-risk cohort for the implantation of a durable ventricular assist device at the time of presentation. Our study showed that ST-MCS could restore the end-organ function and hemodynamics before durable LVAD implantation. In particular, ST-MCS can optimize renal function that has been reported as an important risk factor for overall survival after durable LVAD implantation. ${ }^{13-16}$ In the refractory cardiogenic shock setting, it is difficult to predict end-organ function reversibility. We believe that the bridging strategy using ST-MCS is more rational for elucidating a patient's appropriate candidacy 
TABLE 4. Baseline characteristics comparison according to right ventricular assist device use in the bridge-to-bridge group

\begin{tabular}{|c|c|c|c|}
\hline & $\begin{array}{c}\operatorname{RVAD}(-) \\
(\mathbf{n}=\mathbf{3 3})\end{array}$ & $\begin{array}{c}\operatorname{RVAD}(+) \\
(\mathbf{n}=\mathbf{1 2})\end{array}$ & $P$ value \\
\hline Age $(y)$ & $54.1 \pm 10.2$ & $50.8 \pm 11.4$ & .354 \\
\hline $\mathrm{BSA}\left(\mathrm{m}^{2}\right)$ & $1.93 \pm 0.24$ & $2.16 \pm 0.34$ & .033 \\
\hline BMI $\left(\mathrm{kg} / \mathrm{m}^{2}\right)$ & $24.4 \pm 7.8$ & $31.9 \pm 8.2$ & .016 \\
\hline \multicolumn{4}{|l|}{ Pre-ST-MCS parameters } \\
\hline Lactate $(\mathrm{mmol} / \mathrm{L})$ & $4.26 \pm 2.81$ & $4.16 \pm 1.58$ & .930 \\
\hline $\mathrm{CVP}(\mathrm{mm} \mathrm{Hg})$ & $14.1 \pm 6.1$ & $20.7 \pm 7.7$ & .028 \\
\hline $\operatorname{mPAP}(\mathrm{mm} \mathrm{Hg})$ & $34.4 \pm 9.0$ & $34.3 \pm 9.2$ & .984 \\
\hline $\mathrm{BUN}(\mathrm{mg} / \mathrm{dL})$ & $41.7 \pm 25.4$ & $40.4 \pm 19.2$ & .892 \\
\hline Creatinine (mg/dL) & $1.75 \pm 0.87$ & $1.80 \pm 0.77$ & .880 \\
\hline $\operatorname{AST}(\mathrm{IU} / \mathrm{dL})$ & $50(30-220)$ & $165(40-502)$ & .704 \\
\hline ALT (IU/dL) & $41(19-86)$ & $111(28-423)$ & .255 \\
\hline T-bil (mg/dL) & $1.2(0.9-1.9)$ & $2.6(1.5-6.7)$ & .010 \\
\hline Albumin (mg/dL) & $3.19 \pm 0.56$ & $3.53 \pm 0.44$ & .101 \\
\hline MELD score & $17.3 \pm 7.0$ & $23.2 \pm 11.4$ & .066 \\
\hline HMRS & $2.42 \pm 1.14$ & $3.07 \pm 3.02$ & .339 \\
\hline Duration of ST-MCS (d) & $14(9-26)$ & $15(4-32)$ & .927 \\
\hline \multicolumn{4}{|l|}{ Predurable LVAD parameters } \\
\hline $\mathrm{CVP}(\mathrm{mm} \mathrm{Hg})$ & $7.9 \pm 4.3$ & $8.5 \pm 2.1$ & .797 \\
\hline mPAP $(\mathrm{mm} \mathrm{Hg})$ & $27.9 \pm 7.3$ & $22.7 \pm 7.4$ & .310 \\
\hline Sodium $(\mathrm{mmol} / \mathrm{L})$ & $134.2 \pm 5.5$ & $134.2 \pm 5.7$ & .998 \\
\hline Potassium $(\mathrm{mmol} / \mathrm{L})$ & $4.0 \pm 0.5$ & $4.5 \pm 0.6$ & .021 \\
\hline WBC $(\times 1000$ counts $/ \mathrm{mL})$ & $12.2 \pm 4.2$ & $12.0 \pm 2.5$ & .890 \\
\hline Hemoglobin $(\mathrm{g} / \mathrm{dL})$ & $9.1 \pm 1.4$ & $9.3 \pm 1.5$ & .642 \\
\hline BUN $(\mathrm{mg} / \mathrm{dL})$ & $23.6 \pm 11.7$ & $20.0 \pm 13.2$ & .387 \\
\hline Creatinine (mg/dL) & $1.18 \pm 0.58$ & $1.05 \pm 0.55$ & .477 \\
\hline $\operatorname{AST}(\mathrm{IU} / \mathrm{dL})$ & $32(21-77)$ & $39(30-387)$ & $>.999$ \\
\hline ALT (IU/dL) & $21(16-73)$ & $39(19-125)$ & .177 \\
\hline T-bil (mg/dL) & $1.20(0.55-2.35)$ & $1.45(0.95-2.98)$ & .146 \\
\hline Albumin (mg/dL) & $3.09 \pm 0.57$ & $3.15 \pm 0.52$ & .752 \\
\hline INR & $1.22 \pm 0.17$ & $1.53 \pm 0.67$ & .045 \\
\hline MELD score & $11.0 \pm 5.0$ & $11.5 \pm 8.2$ & .840 \\
\hline HMRS & $1.54 \pm 0.78$ & $1.72 \pm 1.15$ & .584 \\
\hline \multicolumn{4}{|l|}{ Operative parameters } \\
\hline Aortic valve procedure, $\mathrm{n}(\%)$ & $7(21)$ & $3(25)$ & $>.999$ \\
\hline Tricuspid valve procedure, $\mathrm{n}(\%)$ & $4(12)$ & $4(33)$ & .181 \\
\hline Packed red blood cell, units & $5.1 \pm 2.8$ & $4.8 \pm 4.3$ & .756 \\
\hline Fresh-frozen plasma, units & $5.1 \pm 3.0$ & $7.3 \pm 4.7$ & .099 \\
\hline Platelets, units & $14.2 \pm 6.9$ & $19.5 \pm 10.6$ & .065 \\
\hline CPB time (min) & $121 \pm 33$ & $187 \pm 79$ & $<.001$ \\
\hline Aortic crossclamp, n (\%) & $10(30)$ & $5(42)$ & .496 \\
\hline
\end{tabular}

for a durable ventricular assist device, optimizing the patient's condition, and aiming at an appropriate goal in each patient (ie, recovery, transplantation, durable ventricular assist device) in patients with an INTERMACS profile I complicated by end-organ failure.

On the other hand, this study elucidated possible disadvantages or limitations of the BTB strategy. Despite the optimization of hemodynamics and renal function, the BTB group had inferior early and late outcomes compared with the nonbridging group. This worse survival in the BTB group can be largely explained by severe right heart failure after durable LVAD implantation. The rate of RVAD use was high up to $27 \%$. The outcome was comparable between BTB and nonbridging groups in patients who did not require postoperative RVAD or in those who could be discharged after durable LVAD insertion. Postoperative severe right ventricular failure requiring an RVAD has been known to be a significant risk factor for death after LVAD insertion. ${ }^{17,18}$ In our study, postoperative severe right ventricular failure requiring RVAD also was an 
independent predictor for early and late death. Several studies reported that cardiogenic shock due to LV pump failure can deteriorate intrinsic right ventricular function through pulmonary hypertension, pulmonary endothelial dysfunction, proinflammatory cytokine levels, or myocardial ischemia. ${ }^{19-21}$ The INTERMACS annual report revealed that patients with an INTERMACS profile I developed postoperative right heart failure more frequently than those with other profiles. ${ }^{4}$ Others showed that an INTERMACS profile I or preoperative ECMO use was a risk factor for requiring postoperative RVAD after durable LVAD insertion. ${ }^{4,22,23}$ In these reports, preoperative central venous pressure level was a predictor of postoperative severe right ventricular failure requiring RVAD. Hemodynamic indices are reported to be reliable and strong predictors for severe right heart failure after LVAD insertion. ${ }^{17,18,22-24}$ However, in the present study, all hemodynamic values before durable LVAD in the BTB group were better than those in the nonbridging group, because the majority of $\mathrm{BTB}$ cases received right ventricular unloading by ECMO or CentriMag RVAD. These findings suggest that hemodynamic indices do not reflect true right ventricular function, and we may underestimate the possibility of biventricular failure in patients in refractory cardiogenic shock.

To avoid unplanned RVAD insertion, assessment of right ventricular function is essential before durable LVAD insertion. In patients with CentriMag biventricular support, we routinely performed an RVAD weaning test to assess right ventricular function in the loading condition. However, in patients with ECMO, it is difficult to assess right ventricular function in the loading condition without compromising systemic flow in the setting of failed LV. In our subgroup analysis (Table 4), patients who required an RVAD after durable LVAD insertion had higher central venous pressure and INR values before receiving ST-MCS, suggesting that those had worse right ventricular function. This result suggests that hemodynamic indices before ST-MCS may be a predictor for severe right ventricular failure after durable LVAD implantation. However, further sophisticated methods to estimate accurate right ventricular function in patients with ST-MCS are warranted.

Various types of ST-MCS have been developed and are available now for the BTB strategy. The role of using a percutaneous device has rapidly increased because of its convenience and less invasiveness. ${ }^{25}$ However, there remain limitations, especially in power, durability, requirement of special skill for insertion, and a patient's immobility. ${ }^{26}$ Although a temporary ventricular assist device such as the CentriMag has the advantage of providing sufficient support, durability, and mobility, the standard technique requires a median sternotomy and the use of cardiopulmonary bypass. ${ }^{7}$ Currently, there is no consensus regarding the choice of ST-MCS for the BTB strategy. Our subgroup analysis demonstrated that CentriMag device support could provide longer support time with better restoration of hepatic function. The incidence of severe right ventricular failure requiring RVAD and in-hospital mortality was relatively higher in patients bridged with a percutaneous device, although the small number of patients precludes a definitive conclusion. A further study including a larger number of patients is required to determine the optimal choice of device and timing of conversion to durable LVAD.

Intraoperative factors were important to avoid postoperative RVAD. In the present study, patients with postoperative RVAD required a significantly longer cardiopulmonary bypass time and a trend of more blood products transfusion than patients without RVAD. Longer cardiopulmonary bypass time and more blood product transfusions deteriorate right ventricular function. ${ }^{24}$ In patients with the CentriMag device, we often encountered dense adhesions around the cannulae that certainly increased the surgical complexity. It is critically important to minimize surgical invasiveness to avoid postoperative right heart failure. Since 2015, we have changed our strategy to spare the sternum and facilitate the second definitive surgery. We currently perform minimally invasive CentriMag placement using a minithoracotomy.

The BTB group had a higher myocardial recovery rate $(13 \%)$ than the nonbridging population $(1 \%)$ (Table E3). This rate was higher than the rate in the INTERMACS report. ${ }^{4}$ The reason for this difference can be explained by the differences in age and causes. Our BTB cohort included younger patients and patients in acute failure, such as those with acute myocardial infarction, fulminant myocarditis, or postcardiotomy shock. In the present study, 1 patient $(5 \%)$ of 20 with acute myocardial infarction, $2(100 \%)$ of 2 patients with fulminant myocarditis, and $2(40 \%)$ of 5 patients with postcardiotomy shock achieved myocardial recovery. Younger patients with a nonischemic cause and short duration of heart failure symptoms have a good chance for myocardial recovery after LVAD support. ${ }^{27,28}$ It seems reasonable to administer optimal heart failure medication and evaluate serial cardiac function for possible myocardial recovery after durable LVAD implantation in selected patients who initially presented with refractory cardiogenic shock and an acute failure cause.

\section{Study Limitations}

There are several limitations to the present study. First, this was a single-center retrospective study. It remains unclear whether the BTB strategy is superior to the primary implantation of a durable LVAD for patients in refractory cardiogenic shock because of the lack of controls. In addition, only patients who had durable LVAD insertion were evaluated, and patients who died or recovered during ST-MCS support were not analyzed. Third, the percutaneous ST-MCS included various device 
types. Because the number of patients was small, we lack the statistical power to draw a conclusion regarding the optimal bridge strategy.

\section{CONCLUSIONS}

ST-MCS can optimize patients in refractory cardiogenic shock and serve as a bridge to durable LVAD implantation. However, early and late mortality rates after durable LVAD implantation are high because of unrecognized severe right ventricular failure requiring RVAD support.

\section{Conflict of Interest Statement}

Y.N. has received consulting fees from Thoratec Corp. All other authors have nothing to disclose with regard to commercial support.

\section{References}

1. Estep JD, Starling RC, Horstmanshof DA, Milano CA, Selzman CH, Shah KB, et al. Risk assessment and comparative effectiveness of left ventricular assist device and medical management in ambulatory heart failure patients: results from the ROADMAP Study. J Am Coll Cardiol. 2015;66:1747-61.

2. Miller LW, Pagani FD, Russell SD, John R, Boyle AJ, Aaronson KD, et al. Use of a continuous-flow device in patients awaiting heart transplantation. $N$ Engl $J$ Med. 2007;357:885-96.

3. Slaughter MS, Rogers JG, Milano CA, Russell SD, Conte JV, Feldman D, et al. Advanced heart failure treated with continuous-flow left ventricular assist device. $N$ Engl J Med. 2009;361:2241-51.

4. Kirklin JK, Naftel DC, Pagani FD, Kormos RL, Stevenson LW, Blume ED, et al. Seventh INTERMACS annual report: 15,000 patients and counting. J Heart Lung Transplant. 2015;34:1495-504.

5. Riebandt J, Haberl T, Mahr S, Laufer G, Rajek A, Steinlechner B, et al. Preoperative patient optimization using extracorporeal life support improves outcomes of INTERMACS Level I patients receiving a permanent ventricular assist device. Eur J Cardiothorac Surg. 2014;46:486-92.

6. Shah P, Smith S, Haft JW, Desai SS, Burton NA, Romano MA, et al. Clinical outcomes of advanced heart failure patients with cardiogenic shock treated with temporary circulatory support before durable LVAD implant. ASAIO J. 2016; 62:20-7.

7. Takayama H, Soni L, Kalesan B, Truby LK, Ota T, Cedola S, et al. Bridge-todecision therapy with a continuous-flow external ventricular assist device in refractory cardiogenic shock of various causes. Circ Heart Fail. 2014;7:799-806.

8. Truby L, Mundy L, Kalesan B, Kirtane A, Colombo PC, Takeda K, et al. Contemporary outcomes of venoarterial extracorporeal membrane oxygenation for refractory cardiogenic shock at a large tertiary care center. ASAIO J. 2015;61: 403-9.

9. Takayama H, Yang JA, Naka Y. Tips on tuning each device: technical pearls. Cardiol Clin. 2011;29:551-6.

10. Cowger J, Sundareswaran K, Rogers JG, Park SJ, Pagani FD, Bhat G, et al. Predicting survival in patients receiving continuous flow left ventricular assist devices: the HeartMate II risk score. J Am Coll Cardiol. 2013;61:313-21.

11. Boyle AJ, Ascheim DD, Russo MJ, Kormos RL, John R, Naka Y, et al. Clinical outcomes for continuous-flow left ventricular assist device patients stratified by pre-operative INTERMACS classification. J Heart Lung Transplant. 2011;30: $402-7$.

12. Adamo L, Nassif M, Tibrewala A, Novak E, Vader J, Silvestry SC, et al. The Heartmate Risk Score predicts morbidity and mortality in unselected left ventricular assist device recipients and risk stratifies INTERMACS class 1 patients. JACC Heart Fail. 2015;3:283-90.

13. Butler J, Geisberg C, Howser R, Portner PM, Rogers JG, Deng MC, et al. Relationship between renal function and left ventricular assist device use. Ann Thorac Surg. 2006;81:1745-51.

14. Lietz K, Long JW, Kfoury AG, Slaughter MS, Silver MA, Milano CA, et al. Outcomes of left ventricular assist device implantation as destination therapy in the post-REMATCH era: implications for patient selection. Circulation. 2007;116: 497-505.
15. Sandner SE, Zimpfer D, Zrunek P, Rajek A, Schima H, Dunkler D, et al. Renal function and outcome after continuous flow left ventricular assist device implantation. Ann Thorac Surg. 2009;87:1072-8.

16. Yoshioka D, Sakaguchi T, Saito S, Miyagawa S, Nishi H, Yoshikawa Y, et al. Predictor of early mortality for severe heart failure patients with left ventricular assist device implantation. Circ J. 2012;76:1631-8.

17. Kormos RL, Teuteberg JJ, Pagani FD, Russell SD, John R, Miller LW, et al. Right ventricular failure in patients with the HeartMate II continuous-flow left ventricular assist device: incidence, risk factors, and effect on outcomes. J Thorac Cardiovasc Surg. 2010;139:1316-24.

18. Takeda K, Naka Y, Yang JA, Uriel N, Colombo PC, Jorde UP, et al. Outcome of unplanned right ventricular assist device support for severe right heart failure after implantable left ventricular assist device insertion. J Heart Lung Transplant. 2014;33:141-8.

19. Chan CM, Klinger JR. The right ventricle in sepsis. Clin Chest Med. 2008;29: 661-76. ix.

20. Lahm T, McCaslin CA, Wozniak TC, Ghumman W, Fadl YY, Obeidat OS, et al Medical and surgical treatment of acute right ventricular failure. J Am Coll Cardiol. 2010;56:1435-46.

21. Meldrum DR. Tumor necrosis factor in the heart. Am J Physiol. 1998;274: R577-95.

22. Saito S, Sakaguchi T, Miyagawa S, Nishi H, Yoshikawa Y, Fukushima S, et al Recovery of right heart function with temporary right ventricular assist using a centrifugal pump in patients with severe biventricular failure. J Heart Lung Transplant. 2012;31:858-64.

23. Toda K, Fujita T, Kobayashi J, Shimahara Y, Kitamura S, Seguchi O, et al. Impac of preoperative percutaneous cardiopulmonary support on outcome following left ventricular assist device implantation. Circ J. 2012;76:88-95.

24. Meineri M, Van Rensburg AE, Vegas A. Right ventricular failure after LVAD implantation: prevention and treatment. Best Pract Res Clin Anaesthesiol. 2012;26 217-29.

25. Stretch R, Sauer CM, Yuh DD, Bonde P. National trends in the utilization of short-term mechanical circulatory support: incidence, outcomes, and cost analysis. J Am Coll Cardiol. 2014;64:1407-15.

26. Werdan K, Gielen S, Ebelt H, Hochman JS. Mechanical circulatory support in cardiogenic shock. Eur Heart J. 2014;35:156-67.

27. Goldstein DJ, Maybaum S, MacGillivray TE, Moore SA, Bogaev R, Farrar DJ et al. Young patients with nonischemic cardiomyopathy have higher likelihood of left ventricular recovery during left ventricular assist device support. J Card Fail. 2012;18:392-5.

28. Guglin M, Miller L. Myocardial recovery with left ventricular assist devices. Curr Treat Options Cardiovasc Med. 2012;14:370-83.

Key Words: bridge to bridge, cardiogenic shock, left ventricular assist device, short-term mechanical circulatory support

\section{Discussion}

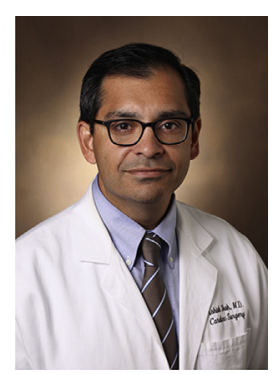

Dr A. Shah (Nashville, Tenn). The authors have reported a single-center series of patients who initially received a short-term circulatory device and then a durable LVAD. The decisions for device support type and timing of durable LVAD implant were not protocolized but rather at the discretion of the shock team and implanting surgeon. This BTB strategy was initially reported in 1999 by Frank Pagani at the University of Michigan, and despite all this time we remain challenged by this group of patients.

This topic is of great interest. The findings of this study are predictable: increased hospital and long-term mortality, 
increased right ventricular failure and need for RVADs, and increased mortality in this cohort.

I have several questions. I am going to focus on this right ventricle failure issue. First, was there any association between the need for an RVAD and the method of shortterm mechanical support? As part of this theme of LV decompression, did better LV decompression reduce the need for a postoperative RVAD?

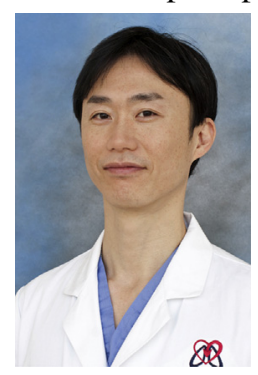

Dr Takeda (New York, NY). We compared our RVAD outcome between the CentriMag device and the ECMO, but the numbers were so small in each group there was no significant difference between the 2 types of device.

Dr Shah. It might be something to explore back at the data set to take a look at how well those patients were

decompressed.

Dr Takeda. Obviously, CentriMag recipients always had an LV apical vent, so it was well decompressed.

Dr Shah. It's something to tease out in your article. As much as I hate to admit it, lactate appears to be an important biochemical marker of end-organ recovery. How did lactate change during the period of short-term support between the patients requiring RVADs and those who did not?

Dr Takeda. Lactate level normalized during the support of short-term mechanical devices. At the time of shock, the mean value was 4.2 , which in all of these cohorts was normalized during support. Therefore, there is no significant difference of lactate level between RVAD versus no RVAD. The patients with a high lactate level at the time of shock tend to die during support, so it's obviously biased. Those patients did not reach bridge to LVAD therapy.

Dr Shah. The article could be enhanced by better assessments of right ventricle risk scores. You used the HMRS II, but I think we have better risk scoring systems. The Kormos, pulmonary artery pulsatility index, or even MELD score appears to discriminate high-risk patients. I encourage you to incorporate that in your article. I think describing the patients who did not survive your bridging strategy will greatly enhance this article. Can you comment on the patients who did not survive?

Dr Takeda. Unfortunately, we didn't calculate the Kormos or pulmonary artery pulsatility index scores, but we calculated the MELD score. In the patients who died, although it was not statistically significant because of the small number of patients, but compared with patients who survived, the MELD score is higher, as in 21 in patients who died but 16 in patients who survived.

Dr Shah. How many patients did not survive to a durable LVAD in the same study period?

Dr Takeda. Approximately 350 patients in shock received ECMO or the CentriMag during this study period: Approximately $40 \%$ died, $40 \%$ reached myocardial recovery, and only $15 \%$ received a durable LVAD. 


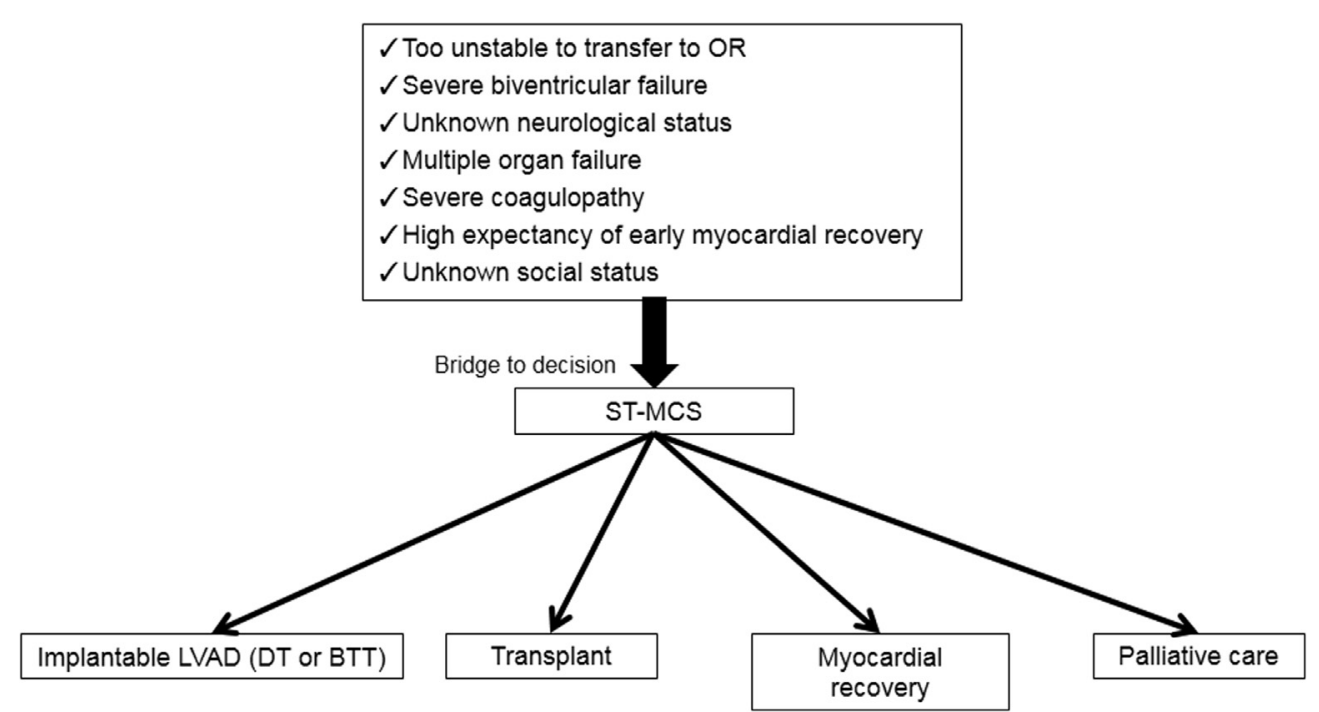

FIGURE E1. Our strategy for patients in refractory cardiogenic shock is shown. OR, Operating room; ST-MCS, short-term mechanical circulatory support; $L V A D$, left ventricular assist device; $D T$, destination therapy; $B T T$, bridge to transplant.
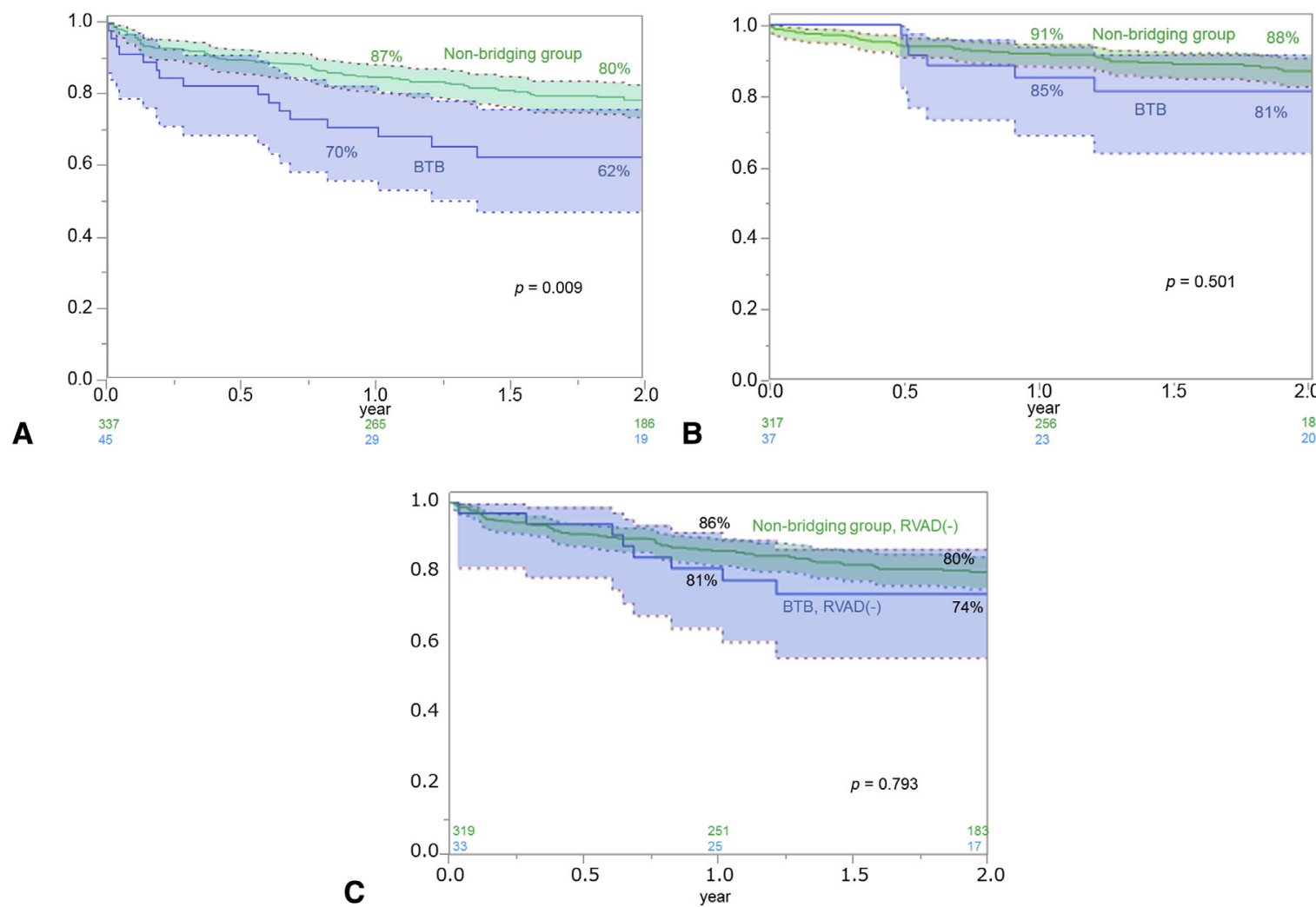

FIGURE E2. Kaplan-Meier survival comparisons between BTB cases $(\mathrm{n}=45)$ and nonbridging cases $(\mathrm{n}=337)$ are shown. A, Overall survival of each group. B, Overall survival after the first discharge. C, Overall survival in patients who did not require an RVAD. RVAD, Right ventricular assist device. 
TABLE E1. Risk factors considered in multivariable analysis

Predurable LVAD valuables

Demographics

Hemodynamics

Comorbidities

Laboratory variables

Mechanical support
Age (y), gender, body surface area $\left(\mathrm{m}^{2}\right)$, body mass index $\left(\mathrm{kg} / \mathrm{m}^{2}\right)$, ischemic or idiopathic dilated vs other cardiomyopathy, previous cardiac operation, device purpose

Ejection fraction $(\%)$, central venous pressure $(\mathrm{mm} \mathrm{Hg})$, mean pulmonary artery pressure $(\mathrm{mm} \mathrm{Hg})$, pulmonary capillary wedge pressure $(\mathrm{mm} \mathrm{Hg})$, systolic blood pressure $(\mathrm{mm} \mathrm{Hg})$, use of inotropes, use of vasopressors

Diabetes mellitus, hypertension, chronic obstructive pulmonary disease, cerebrovascular accident, peripheral vascular disease

Sodium $(\mathrm{mEq} / \mathrm{L})$, blood urea nitrogen $(\mathrm{mg} / \mathrm{dL})$, creatinine $(\mathrm{mg} / \mathrm{dL})$, estimated glomerular filtration rate $\left(\mathrm{mL} / \mathrm{min} / 1.73 \mathrm{~m}^{2}\right)$, AST (IU/dL), ALT (IU/dL), total bilirubin $(\mathrm{mg} / \mathrm{dL})$, total protein $(\mathrm{mg} / \mathrm{dL})$, albumin $(\mathrm{mg} / \mathrm{dL})$, WBC $\left(\times 1000 / \mathrm{mm}^{3}\right)$, hemoglobin $(\mathrm{g} / \mathrm{dL})$, hematocrit $(\%)$, platelet $\left(\times 1000 / \mathrm{mm}^{3}\right)$

Use of ST-MCS, use of IABP

Intraoperative and perioperative valuables

Concomitant surgeries

Aortic valve surgery, mitral valve surgery, tricuspid valve surgery, redo sternotomy

Intraoperative amount of transfusion

Operative time

Packed red blood cell (units), fresh-frozen plasma (units), platelets (units)

Mechanical support

Cardiopulmonary bypass time ( $\mathrm{min})$

$L V A D$, Left ventricular assist device; $A S T$, aspartate transaminase; $A L T$, alanine transaminase; $W B C$, white blood cell; $S T$ - $M C S$, short-term mechanical support; IABP, intra-aortic balloon pump; $R V A D$, right ventricular assist device. 
TABLE E2. Comparison of baseline characteristics between bridge-to-bridge group and nonbridging group

\begin{tabular}{|c|c|c|c|}
\hline & BTB group $(N=45)$ & Nonbridging group $(\mathrm{N}=337)$ & $P$ value \\
\hline Age $(y)$ & $53.2 \pm 10.4$ & $57.4 \pm 14.0$ & .018 \\
\hline Male, n (\%) & $39(87)$ & $271(81)$ & .417 \\
\hline $\operatorname{BSA}\left(\mathrm{m}^{2}\right)$ & $2.00 \pm 0.29$ & $1.95 \pm 0.25$ & .247 \\
\hline $\mathrm{BMI}\left(\mathrm{kg} / \mathrm{m}^{2}\right)$ & $26.5 \pm 8.5$ & $26.2 \pm 5.3$ & .750 \\
\hline BTT/DT & $36 / 9$ & $241 / 96$ & .287 \\
\hline DT $(\%)$ & 20 & 28 & \\
\hline AMI, (\%) & $20(44)$ & $0(0)$ & $<.001$ \\
\hline Nonischemic dilated cardiomyopathy (\%) & $11(24)$ & $176(52)$ & $<.001$ \\
\hline Ischemic dilated cardiomyopathy $(\%)$ & $6(13)$ & $137(41)$ & $<.001$ \\
\hline Fulminant myocarditis $(\%)$ & $2(4)$ & $0(0)$ & .014 \\
\hline Postcardiotomy shock (\%) & $5(11)$ & $0(0)$ & $<.001$ \\
\hline $\mathrm{DM}, \mathrm{n}(\%)$ & $15(33)$ & $115(34)$ & $>.999$ \\
\hline HT, n $(\%)$ & $27(60)$ & $166(49)$ & .205 \\
\hline PVD, n $(\%)$ & $6(13)$ & $20(6)$ & .104 \\
\hline COPD, n $(\%)$ & $5(11)$ & $34(10)$ & .794 \\
\hline CVA, n $(\%)$ & $4(9)$ & $39(12)$ & .802 \\
\hline IABP, n (\%) & $0(0)$ & $91(27)$ & $<.001$ \\
\hline Vasopressor $(\%)$ & $7(16)$ & $30(9)$ & .193 \\
\hline Systolic blood pressure $(\mathrm{mm} \mathrm{Hg})$ & $100.0 \pm 14.4$ & $101.9 \pm 12.9$ & .474 \\
\hline $\mathrm{CVP}(\mathrm{mm} \mathrm{Hg})$ & $8.1 \pm 3.7$ & $10.9 \pm 5.5$ & .046 \\
\hline $\mathrm{mPAP}(\mathrm{mm} \mathrm{Hg})$ & $26.6 \pm 7.4$ & $35.2 \pm 9.5$ & .002 \\
\hline PCWP (mm Hg) & $16.8 \pm 7.0$ & $23.8 \pm 7.9$ & .013 \\
\hline Sodium $(\mathrm{mEq} / \mathrm{L})$ & $134.2 \pm 5.5$ & $133.7 \pm 4.4$ & .566 \\
\hline BUN (mg/dL) & $22.6 \pm 12.1$ & $35.9 \pm 19.5$ & $<.001$ \\
\hline Creatinine $(\mathrm{mg} / \mathrm{dL})$ & $1.15 \pm 0.57$ & $1.59 \pm 0.76$ & $<.001$ \\
\hline $\mathrm{eGFR}\left(\mathrm{mL} / \mathrm{min} / 1.73 \mathrm{~m}^{2}\right)$ & $92.6 \pm 52.7$ & $58.1 \pm 24.4$ & $<.001$ \\
\hline $\operatorname{AST}(\mathrm{IU} / \mathrm{dL})$ & $33(22-82)$ & $23(18-33)$ & .001 \\
\hline ALT (IU/dL) & $24(16-83)$ & $22(15-38)$ & .604 \\
\hline T-bil (mg/dL) & $1.3(0.65-2.35)$ & $1.1(0.7-1.8)$ & .248 \\
\hline Total protein $(\mathrm{mg} / \mathrm{dL})$ & $5.98 \pm 0.95$ & $6.65 \pm 0.77$ & $<.001$ \\
\hline Albumin (mg/dL) & $3.11 \pm 0.55$ & $3.65 \pm 0.52$ & $<.001$ \\
\hline $\mathrm{WBC}\left(\times 1000 / \mathrm{mm}^{3}\right)$ & $12.2 \pm 3.79$ & $8.14 \pm 2.68$ & $<.001$ \\
\hline Hemoglobin $(\mathrm{g} / \mathrm{dL})$ & $9.17 \pm 1.40$ & $11.6 \pm 1.98$ & $<.001$ \\
\hline Hematocrit $(\%)$ & $28.0 \pm 4.0$ & $35.5 \pm 5.5$ & $<.001$ \\
\hline Platelet $\left(\times 1000 / \mathrm{mm}^{3}\right)$ & $185 \pm 77$ & $209 \pm 75$ & .051 \\
\hline MELD score & $11.2 \pm 6.1$ & $13.8 \pm 5.1$ & .006 \\
\hline HMRS & $1.60 \pm 0.89$ & $1.68 \pm 1.00$ & .627 \\
\hline
\end{tabular}

$B T B$, Bridge-to-bridge; $B S A$, body surface area; $A D H F$, acute decompensating heart failure; $A M I$, acute myocardial infarction; $A L T$, alanine transaminase; $A S T$, aspartate transaminase; $B M I$, body mass index; $B U N$, blood urea nitrogen; $C O P D$, chronic obstructive pulmonary disease; $C P R$, cardiopulmonary resuscitation; $C V A$, cerebrovascular accident; $C V V H D$, continuous veno-venous hemodialysis; $C V P$, central venous pressure; $D M$, diabetes mellitus; $D T$, destination therapy; $e G F R$, estimated glomerular filtration rate; $H T$, hypertension; HMRS, HeartMate Risk Score; IABP, intra-aortic balloon pump; INR, international normalization ratio; $M E L D$, Model for End-Stage Liver Disease; $m P A P$, mean pulmonary arterial pressure; $P C W P$, pulmonary capillary wedge pressure; $P V D$, peripheral vascular disease; T-bil, total bilirubin; WBC, white blood cell. 
TABLE E3. Comparison of operative variables and early and late postoperative outcomes between bridge-to-bridge group and nonbridging group

\begin{tabular}{|c|c|c|c|c|}
\hline & BTB group $(N=45)$ & Nonbridging group $(\mathrm{N}=337)$ & OR or HR $(95 \%$ CI $)$ & $P$ value \\
\hline \multicolumn{5}{|l|}{ Durable LVAD } \\
\hline HeartMate II, n (\%) & $41(91)$ & $276(82)$ & & \\
\hline HeartWare, $\mathrm{n}(\%)$ & $4(9)$ & $38(11)$ & & \\
\hline VentrAssist, ${ }^{*} \mathrm{n}(\%)$ & $0(0)$ & $9(3)$ & & \\
\hline DuraHeart,$\dagger \mathrm{n}(\%)$ & $0(0)$ & $8(2)$ & & \\
\hline DeBakey, $\ddagger$ n (\%) & $0(0)$ & $6(2)$ & & \\
\hline \multicolumn{5}{|l|}{ Concomitant valve surgery } \\
\hline Aortic valve surgery, n (\%) & $10(22)$ & $64(19)$ & & .688 \\
\hline Mitral valve surgery, n (\%) & $5(11)$ & $54(16)$ & & .512 \\
\hline Tricuspid valve surgery, $\mathrm{n}(\%)$ & $8(18)$ & $76(23)$ & & .568 \\
\hline PFO closure, $\mathrm{n}(\%)$ & $2(4)$ & $20(6)$ & & $>.999$ \\
\hline CABG, $n(\%)$ & $1(2)$ & $1(0.3)$ & & .222 \\
\hline LV aneurymectomy, $\mathrm{n}(\%)$ & $0(0)$ & $2(0.6)$ & & $>.999$ \\
\hline Redo sternotomy, n (\%) & $33(73)$ & $98(29)$ & & $<.001$ \\
\hline \multicolumn{5}{|l|}{ Transfusion } \\
\hline Packed red blood cell (units) & $5.0 \pm 3.2$ & $1.4 \pm 2.2$ & & $<.001$ \\
\hline Fresh-frozen plasma (units) & $5.8 \pm 3.7$ & $2.8 \pm 2.6$ & & $<.001$ \\
\hline Platelets (units) & $15.8 \pm 8.4$ & $9.2 \pm 6.9$ & & $<.001$ \\
\hline CPB time (min) & $139 \pm 57$ & $91 \pm 44$ & & $<.001$ \\
\hline ICU stay $(\mathrm{d})$ & $13(8-30)$ & $7(5-11)$ & & $<.001$ \\
\hline \multirow{2}{*}{ Hospital stay (d) } & $41(23-65)$ & $26(20-37)$ & & .014 \\
\hline & & & OR & \\
\hline Postoperative RVAD, n (\%) & $12(27)$ & $18(5)$ & $6.42(2.80-14.4)$ & $<.001$ \\
\hline CentriMag RVAD & 11 & 17 & & \\
\hline Percutaneous RVAD & 1 & 1 & & \\
\hline Perioperative complication, $\mathrm{n}(\%)$ & & & OR & \\
\hline Requirement of reexploration & $16(35)$ & $52(16)$ & $2.80(1.38-5.51)$ & .003 \\
\hline Ventricular arrhythmia & $9(20)$ & $82(24)$ & $0.78(0.34-1.62)$ & .582 \\
\hline Atrial fibrillation & $10(22)$ & $79(23)$ & $0.93(0.42-1.90)$ & .856 \\
\hline Sepsis/bacteremia & $10(22)$ & $22(7)$ & $4.09(1.73-9.16)$ & .002 \\
\hline Stroke & $7(16)$ & $20(6)$ & $2.92(1.09-7.08)$ & .028 \\
\hline \multirow[t]{2}{*}{ CVVHD } & $11(24)$ & $26(8)$ & $3.87(1.71-8.37)$ & .002 \\
\hline & & & OR & \\
\hline In-hospital mortality, n (\%) & $8(18)$ & $19(6)$ & $3.62(1.41-8.60)$ & .008 \\
\hline Outcomes at $2 \mathrm{y}, \mathrm{n}(\%)$ & & & HR & \\
\hline Death on LVAD & $14(31)$ & $72(21)$ & $2.31(1.23-4.05)$ & .011 \\
\hline Heart transplant & $19(42)$ & $165(49)$ & $0.88(0.56-1.47)$ & .621 \\
\hline Myocardial recovery & $6(13)$ & $3(1)$ & $18.5(4.83-88.1)$ & $<.001$ \\
\hline Ongoing support & $6(13)$ & $97(29)$ & $0.63(0.45-0.89)$ & .011 \\
\hline Readmission (/patient-y) & & & HR & \\
\hline Right heart failure & 0.10 & 0.11 & $1.08(0.32-2.72)$ & .881 \\
\hline Ventricular arrhythmia & 0.17 & 0.09 & $2.52(0.92-5.91)$ & .069 \\
\hline GI bleeding & 0.34 & 0.19 & $1.69(0.81-3.18)$ & .151 \\
\hline LVAD pocket infection & 0.02 & 0.03 & $0.72(0.04-3.58)$ & .741 \\
\hline Driveline infection & 0.08 & 0.06 & $0.85(0.13-2.89)$ & .824 \\
\hline Stroke & 0.10 & 0.05 & $1.42(0.42-3.66)$ & .529 \\
\hline LVAD thrombosis & 0.10 & 0.07 & $1.51(0.45-3.89)$ & .465 \\
\hline
\end{tabular}

$B T B$, Bridge-to-bridge; $O R$, odds ratio; $H R$, hazard ratio; $C I$, confidence interval; $L V A D$, left ventricular assist device; $P F O$, patent foramen ovale; $C A B G$, coronary artery bypass grafting; $L V$, left ventricular; $C P B$, cardiopulmonary bypass; $I C U$, intensive care unit; $R V A D$, right ventricular assist device; $C V V H D$, continuous venovenous hemodialysis; $G I$, gastrointestinal. *Ventracor, Ltd, Chatswood, Australia. †Terumo Heart, Inc, Ann Arbor, Mich. łMicroMed Cardiovascular, Inc, Houston, Tex. 
TABLE E4. Cox hazard analysis for overall survival in entire cohort $(\mathbf{N}=382)$

\begin{tabular}{|c|c|c|c|c|}
\hline & \multicolumn{2}{|c|}{ Univariate } & \multicolumn{2}{|c|}{ Multivariate } \\
\hline & HR $(95 \%$ CI $)$ & $P$ value & HR $(95 \%$ CI $)$ & $P$ value \\
\hline Age & $1.02(1.00-1.04)$ & .026 & $1.02(1.00-1.05)$ & .032 \\
\hline Use of ST-MCS & $2.02(1.13-3.39)$ & .019 & $1.03(0.45-2.27)$ & .937 \\
\hline Redo & $1.52(0.98-2.34)$ & .060 & $0.78(0.45-1.36)$ & .384 \\
\hline Hemoglobin & $0.88(0.79-0.98)$ & .022 & $0.96(0.83-1.10)$ & .553 \\
\hline Creatinine & $1.46(1.23-1.68)$ & $<.001$ & $1.34(1.12-1.57)$ & .002 \\
\hline Albumin & $0.52(0.35-0.77)$ & .001 & $0.85(0.50-1.44)$ & .542 \\
\hline CPB time & $1.01(1.00-1.01)$ & .001 & $1.00(1.00-1.01)$ & .216 \\
\hline Red blood cell transfusion & $1.19(1.11-1.27)$ & $<.001$ & $1.14(1.02-1.25)$ & .016 \\
\hline Fresh-frozen plasma & $1.13(1.05-1.19)$ & .001 & $1.01(0.92-1.10)$ & .833 \\
\hline Use of postoperative RVAD & $5.14(2.95-8.48)$ & $<.001$ & $4.04(1.97-7.94)$ & $<.001$ \\
\hline
\end{tabular}

$H R$, Hazard ratio; $C I$, confidence interval; ST-MCS, short-term mechanical circulatory support; $C P B$, cardiopulmonary bypass; $R V A D$, right ventricular assist device. 